\title{
The Use of 3D Anthropometric Data for Morphotype Analysis to Improve Fit and Grading Techniques
}

\author{
Alexandra DE RAEVE*, Joris COOLS, Hans BOSSAER \\ Department of Fashion Technology, Member of Knowledge Centre for Fashion \& Textiles, \\ University College Ghent, Belgium
}

\begin{abstract}
Apparel Companies can offer well-fitting clothing to only 30 to $40 \%$ of their target. When addressing new target groups this is often reduced to merely $10 \%$. As a result they miss an enormous potential and there are many obsolete stocks. The cause is due to the following aspects:

- The construction of the basic pattern and the grading to other sizes is based solely on 1D body dimensions. The grading is proportional or rational, but never allometric (taking into account the body proportions). Because the actual morphology of the target is not taken into account the result is a poor fit. Often companies do not dispose of recent data from their target population.

- There are very little 3D sizes available. Several European countries have recently executed a 3D scanning campaign to depict their population, but these data are often not accessible to the garment manufacturers.

- The industry does not have the necessary knowledge and skills to work with 3D measurements. Therefore opportunities that CAD software offer to optimize the fit of garments to their target audience are not being fully exploited.

- Companies do not have the knowledge to grade allometric.

Product development (developing the prototype) is currently very expensive and time consuming. This is due to the lack of 3D data of the target groups and the inefficient use of the possibilities of CAD software packages.
\end{abstract}

Keywords: morphology, sizing, fit, grading

\section{Introduction}

Besides a trendy design, the feeling of wellbeing and comfort in a particular garment are the key triggers for consumers to proceed to purchase. A garment can only be comfortable and flattering to the wearer if the fit is good. Persons having the same size may have a very different body shape so this is not evident. This is shown in figures 1 and 2.
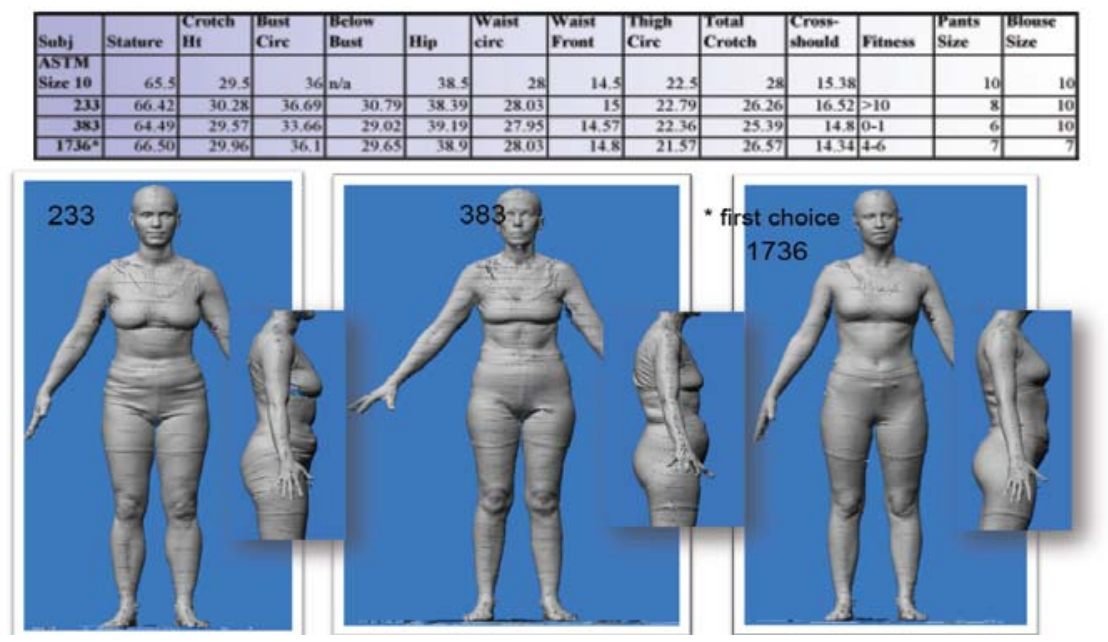

Fig. 1 One size, three body shapes (source SHARP Dummies)

\footnotetext{
*Alexandra.deraeve@hogent.be; +3292488870; www.hogent.be
} 


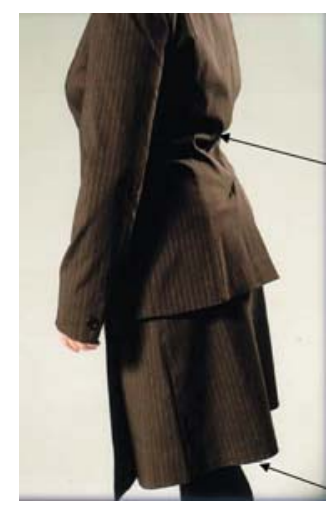

Fig. 2 Right size, wrong fit (source SHARP Dummies)

A good fit is also one of the main parameters to obtain adequate thermophysiological comfort and protection. In the development phase of clothing manufacturers used to focus on the physical (strength, elasticity, insulation, air permeability, ...) and sensory properties (hand, colour, smell) of the textile materials in order to obtain the required comfort level. The two-year research project 'Comfortex' which was started in 2009 by the authors and is now in its finalizing phase has proven that technical components such as clothing design, assembly techniques and especially fit and sizing are for over $50 \%$ responsible for wear comfort and ergonomics of the finished garment.

With the introduction of mass production and ready-to-wear garments, there was no longer attention for a personal fit. Different manufacturers standardized sizes each in their own manner. A study of Just Style ${ }^{1}$ indicates that due to the diversity of people and in many cases the poor quality of body measurement tables most brands can offer well-fitting clothing to only $30-40 \%$ of their target group. When these companies explore new markets, this number is in some cases reduced to a mere $10 \%$. The first years some brands survive with the help of their innovativeness and/or design, but in the subsequent years a proper size range and fit take the upper hand in the decision to purchase. The clothing industry in Belgium and other countries is convinced that size range and fit are a real advantage to compete with cheap imported products $^{2}$. This applies to both companies who distribute their own brands as to contractors. In the case of protective clothing and sportswear a good fit is a must to guarantee the safety and performance ability of the person.

Clothing sizes and fit are difficult concepts to explore and analyze as the relationship between the human body and the garment is complex and often two-fold. The current methods to create sizes and to assess the fit are

$\Rightarrow$ based on the dimensions of the 'ideal' customer being represented by a single fit model

$\Rightarrow$ adapted to other sizes by applying grading rules to the basic pattern for the proportional increases and decreases and

$\Rightarrow$ visual and two-dimensional (in length and width) evaluation comparing linear clothing measurements and body measurements.

Although these methods are useful to evaluate simple fitting outcomes, they are not suited to assess the complexity of the versatile relationship between the body and clothing of a large number of customers with an extended variety of body shapes within one size.

It is therefore not surprising that a study conducted by Kurt Salmon Associates indicates that 50 percent of women claim not to find clothes that fit. For jeans this may be up to $64 \%$. Moreover, poorly fitting protective clothing and sportswear involve serious risks for the wearer. The functioning and performance ability of the wearer is as well adversely affected. Other studies showed that 50 percent of purchases through catalogs are sent back because of problems with the fit.

Companies today are using outdated one-dimensional mean values and percentiles. These data are so deceptive that even with the best intentions errors are included from the start in the product specifications. Moreover, 1D measurement data are blind. They are meaningless regarding the constitution of the measured individuals. When basic patterns are graded to larger and smaller sizes and 3D data of the body are not available, this is mostly an 'educated guess' and even more faults are built in. It is therefore important to have access to 3D models in addition to current $1 \mathrm{D}$ body dimensions in order to adjust the patterns and grading to the variations in body shape.

\footnotetext{
${ }^{1}$ Just-style.com briefings service (July 2010), Sizing a headache for glogalizing apparel industry

${ }^{2}$ Karryn Miller (2010), Studying body size is key to market fit, Just-style.com briefings service
} 


\section{Methodology}

\subsection{Determining the body dimensions of the Belgian population and development of database, standard size charts and frequency tables}

First $0.05 \%$ of the Belgian population, except for pregnant women and children under three, will be measured. This number is the same as the previous measurement campaign from 1990, but higher than in other countries that conducted a sizing survey (France, 11.562 measurements made in 2006 $(0,02 \%$ of the population); Germany, 13.362 measurements in 2008 (0,016 \%); Netherlands, 2000 measurements of 18-65 year olds in $2008(0,04 \%)$ and Great-Britain, 11.000 measurements in 2004 $(0,02 \%)$. The scanning device will be a Telmat SYMCAD 3D body scanner using structured white light.

We will start defining the measurement procedure and a socio-demographic survey.

All measurements and information about the subjects will be stored in a database.

The statistical analysis of anthropometric data: mean, percentiles, standard deviation, correlation, graphic charts, should allow us to make up the standard body size charts and frequency tables. We will consider 5 age groups in the standard charts: 3-13 years, 14-25 years, 26-45 years, 46-64 years and $65+$, both men and women. These charts can then be further divided into clothing that completely covers the body, covering above the waist and below the waist. This will be in harmony with EN 13402 (CEN/TC 248/WG 10: size designation system for clothing). Existing size tables are of the 1D type. A primary dimension is chosen based on the type of clothing (eg. waist circumference). Adjacent intervals are provided $(70-74,74-78,78-82, \ldots)$. The margins are chosen in a way that clothing is comfortable enough without being too broad. The expected values of certain secondary parameters (hip circumference, chest circumference, ...) are also given in intervals. The choice of primary and secondary dimensions is decisive to determine the percentage of the target group that can be dressed appropriate. In current size tables intervals do not overlap. In reality this is only possible if all body types within the population are identical except a scaling factor. This is obviously not the case. For each class of waist circumference we must allow a variation of the secondary dimension that partially covers variations of the waist circumference of neighboring classes. Proposals will be made which will form a more specific classification and allow improved patterns.

Comparing the results of the socio-demographic survey with the size data will allow us to determine whether there is correlation between the two. We will also be able to set up size charts for specific target groups. This will bring the possibilities and potential of mass customization closer to the manufacturers.

\subsection{Study of morphotypes}

Second, the body shapes will be studied. We will do this by Principle Component Analysis.

The population will be divided into four or more body types for men and women that will cover $80 \%$ of the population. This should give us also a good view on the most common abnormalities in a body.

\subsection{Development of an allometric grading technique}

Next an allometric grading technique will be developed.

Grading is a process used to produce clothing in a certain size range. For this, at certain points called cardinal points, dimensional increases or decreases are applied to the pattern to obtain larger or smaller sizes. To establish a relationship between body size and grading technique, the cardinal points must correspond to a landmark on the body which is a horizontal or vertical measurement (grading is done according an $X Y$ coordinate system). Landmarks are the endpoints of a measurement. In proportional grading techniques we note that the cardinal points do not always correspond to landmarks, the breastpoint remains in the same position for all sizes, the increases and decreases are conducted with constant rate and all pattern pieces become larger as the size increases. Even when using a rational grading system that takes the proportions in the basic pattern construction into account, the body shape is not considered. When the actual size differs more from the basic size in which the pattern was made up, it inevitably leads to a poor fit. Body measurements do not increase or decrease proportionally as a person gains or loses weight.

At each cardinal point of a pattern a landmark will be assigned. This measurement will either be horizontal or vertical. A landmark may be connected to only one cardinal point. These points will be graded to the actual body proportions and not proportional. 


\subsection{Processing scan results into usable avatars}

Finally the 3D volumes will be processed into a usable avatar for virtual prototyping to assess the fit. Basic patterns can thus be automatically adjusted to customized patterns which will strongly reduce lead time for product development.

\section{Objectives}

\subsection{Technological objectives}

The primary technological objectives of this project are:

1. Providing companies with the necessary knowledge to develop models and patterns which take the body shape into account. This will require a study of the morphotypes. Several body types will be defined.

2. The companies will be taught how to grade their basic patterns allometric so the fit is optimized.

3. Companies will be offered greater insight into the far unused potential of $2 D$ CAD programs and they will discover the potential of $3 \mathrm{D}$ virtual prototyping.

4. Database consisting the raw anthropometric data

5. Improved size charts

\subsection{Economic value}

The use of 3D body scanners has proven its importance in identifying body size and body form of the population in different countries like the Netherlands, Germany, Spain, Britain and France. The project results will allow the clothing sector to better adjust its sizes and fits to the respective target groups. This will allow them to significantly increase the share of the target group that can be dressed appropriate from $30-40 \%$ to $50-80 \%$. The brand loyalty of the consumers will undoubtedly be increased. The results of the sizing campaign can be used to impart the updated standard body size tables as well as size tables for specific target groups. These tables can be compared with data from other 3D sizing campaigns in Europe, America or Asia. Allometric grading rules will allow manufacturers to adapt all sizes better to the body shape of the target. Now, we see that when sizes differ more from the size of the fit model, the fit gets worse. The time and cost to achieve a good prototype will be halved.

The project results will also be supportive for companies seeking new markets or business models and the retail business.

$\Rightarrow$ The results can be very helpful in preparing a configurator for a mass customization business model.

$\Rightarrow$ The fashion retailer will be given a better understanding of the different body shapes. This will enable him to better support the end user in choosing clothes that suit his or her body shape. Customer satisfaction will increase.

$\Rightarrow$ Within the clothing industry workwear, protective wear and sportswear are growth markets. Between 2004 and 2008 the production of sports clothing increased by $19.4 \%$. It is expected to increase with another $18.75 \%$ by 2014 . The annual growth for workwear is estimated between $2.5 \%$ and $5 \%$. For these products a good fit can be of vital importance and / or mean the difference between gold or silver.

$\Rightarrow$ At the end of the season 10 to $15 \%$ of the collection remains on the shelves. A considerable part of this is simply due to a bad fit.

$\Rightarrow$ In $200821 \%$ of SME's offered products through the Internet. In 2009 this was already $25 \%$. 80 percent of these SME's foresee an increase in internet sales in the coming years. For clothing, the increase is smaller than for other products. The cause lies in the lack of adequate size data. The latter are the key to the growth of e-Commerce for clothing. 50 percent of returned purchases by mail order or over the Internet has its origin in problems with the size and fit. Better measurements and fit will at least halve this figure.

\subsection{Social value}

The project results will ensure that the performance, safety and wellbeing of users is promoted.

Studies already showed that the fit, together with the materials used in sportswear can greatly affect performance of athletes (Swift Skin for cyclists and skaters and Swift Suit from Nike or Fastskin ${ }^{\circledR}$ from Speedo for athletes). The project results will support manufacturers of sportswear in the development of high-performance sportswear.

A common complaint among workers is that the personal protective equipment does not fit well. The project results will contribute in adjusting the protective garments to the needs and desires of the 
individual wearer meaning work and protective clothing will be worn much more consistent so there will be less injuries in case of an accident.

Workstations can also be designed more ergonomic so that the number of workers with back pain will diminish and there will be less absenteeism.

In most Western countries, the population is aging. Between 2010 and 2020 an increase in the number of people over 65 with 200,000 and with 300,000 between 2020 and 2030 is expected (46\%). Old age is not what it used to be. Not only do we all age, we age differently. The New Elderly Person is healthier, wealthier, better educated and more assertive than its predecessor. At an age when their parents were thinking of phasing out quietly, the new 55-plus step in their second adolescence, and they prepare themselves to put the crown on their lives. Seniors today have a busy life, they travel and sport. They also want to dress differently from their predecessors. They want fashionable, colourful and well-fitting clothes for all their activities. Many seniors are faced with a physique that deviates from the standard. This may be merely due to overweight, but also to eg. kyphosis, lordosis or scoliosis. This implies that the fashionable ready-to wear garments offered in the stores does not have the right fit and does not feel comfortable. The project results will ensure that for this specific target group more appropriate garments can be developed.

\section{Acknowledgements}

The authors would like to thank the Flemish agency for innovation by Science and Technology IWT for financial support of the projects 'Comfortex, thermophysiological modeling of active wear for work, protection and sports' and 'Smartfit, research project focused on the determination of updated Belgian size tables, defining body types and creating tools that facilitate mass customization, sustainable design and e-commerce'. This paper is part of the two-year project Smartfit that will start in November 2011. It has relevant stakeholders, including the textile and garment manufacturing federations Fedustria and Creamoda, the Scientific Institute for Public Health and over ten SME's that agreed to co-finance the project.

\section{References}

1. E. Nyssen, J. Cornelis, R. Younckx (1990), Belgische matentabellen voor bovenkleding, Kledingfederatie

2. www.DINbelg2005.be, consulted on 25/08/2010

3. M. Geentjens, Antropometrie, www. gesa.be/antropometrie.pdf, consulted on 20/09/2010

4. EN 13402 CEN/TC 248/WG 10: size designation system of clothing

5. http://www.ergonomiesite.be/antropometrie.htm, consulted on 20/09/2010

6. ISO 8559:1989 Garment Construction and anthropometric surveys - Body dimensions

7. S. Alemany (2008), Anthropometric activities in IBV, WEAR Conference, Paris

8. K.M. Robinette, S. Blackwell, H. Daanen (2002), Civilian American and European Surface Anthropometrie Resource (CAESAR) Final report, Volume 1: Summary

9. D. Caple \& associates Pty Ltd.(2009), Sizing up Australia: How contemporary is the anthropometric data Australian designers use?

10. Sizing, a headache for globalizing apparel industry (2010), Just Style.com

11. K.L. Wuensch (2009), Principal components analysis, core.ecu.edu/psyc/wuenschk/mv/fa/pcaspss.doc

12. C. Berger, F. Piller (2003), Customers as co-designers: The miAdidas mass customization strategy, IEE Manufacturing Engineer, Vol. 82, 42-46

13. F. Piller (2008), Interactive value creation with users and customers, Leading open innovation, Munich: Peter-Pribilla Foundation, 16-24

14. F. Piller (2006), Mass Customization Ein wettbewerbsstrategisches Konzept im informationszeitalter, Springer e-books

15. T. Blecker, G. Friedrich (2006), Mass customization: chalenges and solutions, International series in operations research \& management science, Vol. 87

16. Telmat Industry (2009) Apply a special tracking scenario, training course documentation

17. C.R. Boër, S. Dulio (2007), Mass customization and footwear: myth, salvation or reality?

18. G. Da Silveira, D. Borenstein, F.S. Fogliatto (2001), Mass customization: Literature review and research directions, International Journal of Production Economics, 1-13

19. C. Shu, P. Xi, Z. Azouz (2007) Consistent parameterization and principal component analysis of 3D anthropometry data, WEAR Conference, Bannf

20. D. Veitch (2007), Life-like apparel mannequins from 3D human data, WEAR Conference, Bannf

21. H. Daanen, F. Nennie, M. Rioux (2007), 3D anthropometric data collection, WEAR Conference, Bannf 
22. K. Robinette (2010), 3-D or not 3-D? Benefits and potential of 3D anthropometry, WEAR Conference, Valencia

23. C. Shu (2010), Making 3-D Anthropometric data usable, WEAR Conference, Valencia

24. H. Daanen (2010), Evaluation of Diital human models, WEAR Conference, Valencia

25. D. Veitch (2010), Application of anthropometric data to garment sizing and design via innovative product development tools, WEAR Conference, Valencia

26. S. Allemany, C. Arnaiz (2010), Anthropometric survey of the Spanish female population aimed at the apparel industry, WEAR Conference, Valencia

27. B. Colombier (2010), Anthropometry applied to children products, WEAR Conference, Valencia

28. M. Mochimaru (2010), 4D measurement of skin movement and its application to garment design, WEAR Conference, Valencia

29. http://www.2dix.com/pdf-2011/analysis-of-anthropometric-data-data-clothing-pdf.php consulted on $\underline{21 / 01 / 2011}$ 